\title{
A GOVERNANÇA GLOBAL NO PLANEJAMENTO DAS CIDADES E SUA RELAÇÃO COM O REGIME INTERNACIONAL DAS MUDANÇAS CLIMÁTICAS.
}

\section{GLOBAL GOVERNANCE ON CITY PLANNING AND ITS RELATIONSHIP WITH INTERNATIONAL REGIME ON CLIMATE CHANGE}

\author{
Alcindo Fernandes Goncalves ${ }^{1}$ \\ Jorge Jurado Perez ${ }^{2}$
}

\begin{abstract}
Resumo
Uma das principais preocupações atuais no planeta está relacionada com o meio ambiente, especialmente quanto às mudanças climáticas. De outra parte, o desenvolvimento das cidades e sua expansão é identificado como uma das principais causas que contribuem para a intensificação das mudanças climáticas. Nesse sentido, o objetivo do presente artigo é estudar a relação e comunicação existente entre o regime internacional das mudanças climáticas e a governança global no planejamento das cidades.

O método de pesquisa para a elaboração do presente artigo foi o teórico-dedutivo. Para seu desenvolvimento, o ponto de partida são os conceitos gerais de regimes internacionais e de governança global para posteriormente identificar que, conforme ações e atividades dos diferentes atores no cenário internacional, é possível falar da existência de uma governança global no planejamento das cidades, cujo desenvolvimento se encontra intimamente relacionado com os resultados e objetivos do regime internacional das mudanças climáticas. Além da existência da governança global focada no planejamento das cidades, o artigo enfatiza que as decisões relacionadas com o desenvolvimento das cidades que, a princípio, parecem ter apenas relevância local ao interior dos países, estão sendo discutidas igualmente no cenário internacional.
\end{abstract}

Palavras-chave:Governança Global; Regimes Internacionais; Planejamento das Cidades; Mudanças Climáticas; Gases de Efeito Estufa.

\section{Abstract}

One of the main current concerns on the planet is related to the environment, particularly to climate change. On the other hand, the development of cities and their expansion is identified as one of the main causes contributing to the intensification of climate change. In this regard, the objective of this article is to study the relationship and communication between the international regime on climate change and the global governance on city planning.

The research method for the elaboration of the article was the deductive approach. Thus, the development of this article was based on the understanding of the general concepts of the

\footnotetext{
${ }^{1}$ Doutor em Ciência Politica pela FFLCHUSP. Professor e coordenador do Programa de Pós-Graduação Stricto Sensu em Direito da Universidade Católica de Santos. Universidade Católica de Santos - Brasil. E-mail: alcindo@unisantos.br

2 Mestre em Direito com ênfase em Direito dos Recursos Naturais da Universidade Externado da Colômbia. Doutorando em Direito Ambiental Internacional da Universidade Católica de Santos. Bolsista do Programa Estudantes-Convênio de Pós-Graduação - PEC-PG, da CAPES/CNPq - Brasil. Universidade Católica de Santos. Email: jorgeluis_jurado@hotmail.com
} 
international regime and the global governance. This articles later identifies, according to the actions and activities of the different actors on the international stage, the existence of a global governance on city planning, whose development is closely related to the results and objectives of the international regime on climate change. In this sense, in addition to the existence of this form of global governance focused on city planning, this article shows that the decisions related to the development of cities, which seem only have local relevance, are currently being discussed on the international stage.

Keywords: Global Governance; International Regimes; City Planning; Climate Change; Greenhouse Gases.

\section{Introdução}

Tanto a governança global como os regimes internacionais são dinâmicos e sofrem modificações com o passar do tempo e o surgimento de novas tecnologias e pesquisas sobre temas e assuntos relacionados a eles.

Tal dinamismo, porém, não só significa mudanças no interior dos regimes internacionais ou o surgimento de novas estratégias e ações de governança global. Na realidade, ele se manifesta pelo estabelecimento de diversas relações entre as duas esferas, cuja finalidade é a colaboração mútua e o cumprimento de objetivos comuns, realidade que se apresenta com maior facilidade naqueles casos em que os tópicos sobre os quais se desenvolvem resultam ser interdependentes.

Uma típica relação de interdependência é a existente entre a governança global no planejamento das cidades e o regime internacional das mudanças climáticas, porque, de fato, as cidades são reconhecidas globalmente como grandes geradoras de gases de efeito estufa, foco central da discussão relacionada com as mudanças climáticas.

Assim, o presente artigo busca identificar aqueles pontos nos quais se apresenta a citada relação e refletir sobre o importante papel das cidades no cumprimento de muitas das metas e objetivos do regime internacional das mudanças climáticas.

A relação é tão evidente que Klug, Marengo e Luedemann (2016) consideram como uma novidade da denominada nova agenda urbana precisamente esse diálogo existente entre as orientações do Painel Intergovernamental sobre Mudança do Clima (IPCC) e os princípios de compacidade, conectividade, inclusão e integração definidos para as cidades nos próximos 20 anos.

Neste sentido, o presente artigo está composto por três diferentes itens. No primeiro, é feita a contextualização sobre os conceitos de governança global e regimes internacionais, deixando clara a característica dinâmica deles.

No segundo item, são apresentados o desenvolvimento e conteúdo do que deve ser entendido como governança global no planejamento das cidades, e desde logo é possível identificar algumas das primeiras relações entre ela e o regime internacional das mudanças climáticas.

Finalmente, no terceiro item, são identificadas e desenvolvidas as relações existentes entre a governança global no planejamento das cidades e o regime internacional das mudanças 
climáticas, dando ênfase sobre a importância que têm as cidades para o cumprimento de muitas metas ambientais deste regime.

\section{Governança Global e Regimes Internacionais.}

Antes de aprofundar os temas principais do presente artigo, é importante realizar um estudo sobre os conceitos de governança global e regimes internacionais com a finalidade de estabelecer, com clareza, o cenário que vai ser percorrido nos seguintes itens deste trabalho, entendido como um quadro conceitual geral sobre a matéria.

Assim, para conceituar governança global é, sem dúvida, necessário fazer referência ao fenômeno da globalização, para o qual não existe definição única, mas que pode abranger diversas caraterísticas, como a internacionalização das relações dos Estados e as pessoas, ${ }^{3}$ intensificação das relações comerciais e trânsito de pessoas e informação ao redor do mundo ${ }^{4}$, sua desterritorialização ${ }^{5}$ e a perda de importância e protagonismo das fronteiras dos Estados-nação ${ }^{6}$, as quais em alguns casos de integração de países podem até desaparecer.

Partindo do contexto anterior e com o desenvolvimento da globalização e o surgimento de novos desafios e questões derivados das relações internacionais dos Estados e mesmo dos indivíduos, apresentou-se como necessidade no cenário internacional trabalhar em soluções conjuntas e algumas vezes globais para os diferentes problemas que hoje ultrapassam as fronteiras dos Estados e sua capacidade de atuação frente aos mesmos.

Neste ponto surge o termo governança global, que, segundo palavras de Kotzias e Da Silveira (apud GONÇALVES e REI, 2015, p. 16), pressupõe novas formas de interação entre os governos e a sociedade civil com a finalidade de encontrar interesses comuns e formas cooperativas, cujo objetivo e resultado pode ser a solução de diversos problemas e o estabelecimento de planos de ação para enfrentar fenômenos e contingências que requerem a aplicação de medidas conjuntas desde diferentes setores.

Em suma, a definição de governança estabelecida em 1995 pela Comissão das Nações Unidas sobre Governança Global estabelece que é a soma de possibilidades que diferentes atores, tanto públicos como privados, utilizam para atender seus assuntos comuns, considerando que se trata de um processo continuo no qual as divergências permitem a adoção de ações cooperativas para sua solução (MAUAD, 2014, p. 19).

Do mesmo modo e estudando igualmente a anterior definição de governança, Alcindo Gonçalves (GONÇALVES; COSTA, 2011, p. 53) identifica três aspectos fundamentais: a) seu caráter instrumental, segundo o qual a governança é meio e processo capaz de produzir resultados

\footnotetext{
${ }^{3}$ Segundo Bento (2007, p. 130-133), existem duas definições que ajudam a compreender a dimensão de internacionalização presente no conceito de globalização, as quais são: a) David Held e Anthony McGrew, os quais descrevem a globalização como um processo de intensificação dos fluxos transfronteiriços de interação social, o qual gera diferentes impactos locais na hora de regular os fluxos de mercadorias, capitais, informações, ideias, pessoas, substâncias poluentes ou contaminantes, etc.; b) Robert Keohane e Joseph Nye, os quais caracterizam a globalização como aumento do fenômeno do globalismo e a intensificação das redes de interdependência, a qual significa que cada vez mais eventos ocorridos em uma parte do globo repercutem em lugares distantes.

${ }^{4}$ Ibid.

${ }^{5}$ Bento (2007) utiliza essa palavra para se referir a uma reconfiguração da geografia, de maneira que o espaço social deixa de ser organizado conforme o principio da territorialidade.

${ }^{6}$ Bresser-Pereira (2017, p. 158) define Estado-nação como um tipo de sociedade político-territorial soberana, formada por uma nação, um Estado e um território, e como forma de poder territorial imposta nas sociedades modernas a partir da revolução capitalista em substituição aos feudos e aso impérios antigos.
} 
eficazes; b) a participação ampliada nos processos de decisão, porquanto envolve tanto a participação estatal como a de atores não governamentais; c) o consenso e persuasão como mecanismo para a adoção das ações cooperativas globais.

Em consequência, um exemplo de questões globais que implicam a adoção de medidas cooperativas por parte de diferentes atores pode ser encontrado na temática ambiental, porque, segundo Gonçalves (Ibid, p. 85), não são questões circunscritas em territórios nacionais ou mesmo regionais, sendo fundamental então a abordagem global das mesmas, já que suas consequências e efeitos atingem todo o planeta, situação que para Ivanova (2009, p. 159-162) torna indispensável o papel das instituições internacionais.

Neste sentido, Ivanova (2009) ressalta as atividades e funções do Programa das Nações Unidas para o Meio Ambiente (PNUMA) que, em sua opinião, é uma "organização âncora" em matéria ambiental, cuja criação estabeleceu as bases da arquitetura da governança ambiental global, sistema que, após vários anos de funcionamento, requer uma transição de políticas nacionais para uma ação coletiva que promova o planejamento institucional de resultados efetivos, eficientes e equitativos (Ibid. p. 175).

De outra parte e em relação aos regimes internacionais, devemos indicar que Krasner (1983, p. 1-5) os define como conjunto de princípios, normas, regras e procedimentos de tomada de decisões, implícitos ou explícitos, em torno do qual as expectativas dos diferentes atores convergem e cujo foco central está situado em uma determinada área das relações internacionais.

A definição de Krasner parece ser bastante clara, mas ela recebeu críticas, como, por exemplo, a elaborada por Young (apud HASENCLEVER; MAYER; RITTBERGER, 1997, p. 11-12), que aponta que a definição de Krasner é realmente só uma lista de elementos que são difíceis de diferenciar conceitualmente e que muitas vezes se sobrepõem em situações do mundo real.

Em obra posterior, Young (2010, p. 1-22) identifica como umas das principais caraterísticas dos regimes internacionais sua complexidade e dinamismo. Tanto é assim, que no caso dos regimes internacionais que fazem parte da governança ambiental, estabelece como padrões de mudança as seguintes possibilidades:

a) O desenvolvimento progressivo;

b) O equilíbrio pontual ${ }^{8}$;

c) O desenvolvimento travado;

d) $O$ desvio ${ }^{10}$;

e) $O$ colapso $^{11}$.

\footnotetext{
7 Para Young (2010, p. 9-10), este padrão de mudança se apresenta nos casos de regimes internacionais que começam seu funcionamento com uma série de princípios, direitos, regras, normas e procedimentos de tomada de decisões contidos em um quadro geral, como, por exemplo, as convenções quadro, mas que com o passar do tempo são desenvolvidos através de diferentes emendas e protocolos.

${ }^{8}$ Segundo Young (Ibid p. 10-11), ocorre nos casos em que os regimes enfrentam tensões periódicas que desafiam sua capacidade de se ajustar, ao mesmo tempo em que desencadeiam episódios de construção do regime em razão de sua natureza de desenvolvimento progressivo.

${ }^{9}$ Ocorre quando os regimes começam de maneira promissora, mas depois enfrentam barreiras ou obstáculos que bloqueiam seu desenvolvimento futuro (Ibid, p. 11).

${ }^{10}$ Engloba os regimes internacionais ambientais que são criados para um proposito, mas depois são redirecionados de uma forma que contraria o proposito original (Ibid, p. 12).

${ }^{11}$ Acontece quando o regime atravessa algum limiar, que faz que termine em pouco tempo ou que sofra um grave declínio que transforma o regime em letra morta, embora continue existindo no papel. (Ibid. p. 12-13).
} 
Com os conceitos expostos até o momento, é possível identificar como semelhança entre a governança e os regimes internacionais sua característica dinâmica, uma vez que as constantes mudanças presentes no mundo real em que se desenvolvem matérias objeto de regulamentação inevitavelmente terão seu efeito na forma de realizar ou desenvolver a governança global e no conteúdo próprio de determinado regime internacional.

Partindo da definição de regime internacional elaborada por Krasner exposta acima, Gonçalves (GONÇALVES; COSTA, Op. Cit, p. 54-55) argumenta que também é possível estabelecer uma aproximação entre os conceitos de governança e regimes internacionais, que deriva da dimensão instituciona $\left.\right|^{12}$ da primeira, presente na relação da governança com arranjos de natureza institucional ou na importância de estabelecer regras que possam contribuir na solução de conflitos e promover a cooperação entre atores sociais.

Não obstante as semelhanças e aproximações estabelecidas entre governança global e regimes internacionais, não é possível falar desses conceitos como se fossem um só. Pelo contrário, com a finalidade de deixar clara a diferença, Gonçalves (Ibid. p. 56) manifesta que governança seria a totalidade de maneiras pelas quais são administrados os problemas comuns e, na medida em que a governança busca a solução dos mesmos, os regimes internacionais seriam uma das possibilidades de solução.

Neste sentido, o mesmo autor aponta que, enquanto a governança tem um caráter mais amplo e aberto, os regimes estão aplicados a uma questão especifica ou, pelo menos, a um conjunto limitado de questões (Ibid. p. 57).

Enfim, para tentar estabelecer uma diferença entre governança global e regime internacional, poder-se-ia falar de gênero e espécie. Essa tentativa resulta um pouco forte e poderia levar a intepretações dos conceitos como cenários sem relação alguma, por isso, para efeitos do presente trabalho se prefere estabelecer, baseados nas definições acima estudadas, que os regimes internacionais são uma forma de desenvolvimento da governança global em uma matéria ou tema especifico, fazendo parte da mesma e sem corresponder a uma instituição distante desta.

Esclarecidos os conceitos de governança global e regimes internacionais, nos seguintes itens é possivel observar como a dinâmica destes resulta refletida no surgimento de relações entre diversos tipos de governança e regimes internacionais, cujo desenvolvimento ajuda de alguma forma na materialização dos objetivos de cada um.

\section{Sobre a governança global no planejamento das cidades.}

Falar de governança global no planejamento das cidades (GPC) poderia para alguns parecer sem sentido, porque normalmente a forma em que se planejam as cidades resulta de um conjunto de atividades de aplicação local que muitas vezes se localizam longe do cenário internacional. No presente item, porém, será observado como o desenvolvimento das cidades e seu planejamento estão nas discussões de diversos atores e instrumentos internacionais.

\footnotetext{
${ }^{12}$ Neste ponto é importante não confundir os conceitos de instituições e organizações. As primeiras, em palavras de Gonçalves (GONÇALVES; COSTA. Op. Cit. p. 55), devem entender-se as regras de jogo ou, segundo Young (apud GONÇALVES; COSTA. Ibid), são o "conjunto de regras ou convenções (tanto formais como informais) que definem uma prática social, atribuem papéis e participantes individuais nessa prática, e guiam as interações entre os ocupantes desses papéis". Organizações são então "entidades materiais que possuem localizações físicas (ou sedes), escritórios, pessoal, equipamento e orçamentos" (YOUNG, 1989, apud GONÇALVES; COSTA. Op. Cit. p. 56).
} 
Em tal sentido, uma primeira aproximação sobre a discussão internacional do planejamento das cidades está nos princípios 14 e 15 da Declaração de Estocolmo sobre Meio Ambiente Humano assinada em 1972, porque os mesmos fazem referência às atividades de planificação que devem desenvolver os Estados. Especificamente, o princípio 15 indica que se deve aplicar a planificação aos agrupamentos humanos e à urbanização, com a finalidade de evitar perdas no meio ambiente (ONU, 1972).

Em 1976 foi realizada a primeira Conferência das Nações Unidas sobre Assentamentos Humanos (Habitat I), na cidade de Vancouver (Canadá), cujo resultado foi a Declaração de Vancouver sobre Assentamentos Humanos, na qual os países reconheceram a necessidade de estímulo de assentamentos urbanos sustentáveis (GALINDO; MONTEIRO, 2016), já que o problema não é um tópico que possa ser abordado de forma isolada das questões sociais e econômicas e que as inadequadas circunstâncias de vida de um grande número de pessoas estão diretamente relacionadas, entre outras causas, pela urbanização descontrolada (ONU, 1976).

Um resultado importante da realização da Conferência Habitat I foi a criação, em 1978, do Programa das Nações Unidas para os Assentamentos Humanos, também conhecido como ONUHabitat, agência da ONU focada em temas de urbanização sustentável e assentamentos humanos, cuja função principal é o desenvolvimento urbano social, econômico e ambientalmente sustentável com o objetivo de proporcionar uma moradia adequada para todas as pessoas (ONU, 2018).

Posteriormente, na Carta Mundial da Natureza assinada em 1982, embora não exista referência específica ao planejamento das cidades ou processo de urbanização, podem ser encontradas algumas menções gerais sobre as atividades de planificação. Na parte relativa às Funções da Carta, a de número 8 afirma que, na formulação dos planos de longo prazo para o desenvolvimento econômico, crescimento da população e melhoria das condições de vida, deve ser levada em devida conta a capacidade de longo prazo dos sistemas naturais para garantir a subsistência e assentamento das populações.

Além disso, no tópico relativo à Implementação da Carta, o item 16 declara que todo planejamento deve incluir, entre os elementos essenciais, a formulação de estratégias para a conservação da natureza e o estabelecimento de inventários de ecossistemas, os quais devem ser devidamente divulgados à população, caraterísticas que não resultam indiferentes ao planejamento urbano desenvolvido na atualidade em muitas cidades do mundo.

Em 1987, com a publicação do informe "Nosso Futuro Comum", também conhecido como "Relatório Brundtland", o tópico da urbanização foi novamente protagonista no cenário internacional.

O informe fala sobre o grande desafio urbano no mundo todo e apresenta dados sobre o crescimento rápido das cidades e as consequências deste fenômeno, como o aumento da população, o maior uso de carros, o aumento de fábricas e indústrias e, portanto, o incremento da poluição urbana, especialmente do ar das cidades (ONU, 1987).

Igualmente, o citado informe alerta sobre o aumento dos assentamentos ilegais no interior das cidades e a deterioração do meio ambiente urbano, razão pela qual recomenda a planificação de cidades menores, devidamente integradas com as áreas rurais, focadas na melhoria da qualidade de vida das pessoas, o adequado acesso à água e cujos sistemas de transporte sejam ambientalmente sustentáveis (Ibid). 
Já como resultado da Conferência das Nações Unidas sobre o Meio Ambiente e Desenvolvimento realizada no Rio de Janeiro em 1992, há a elaboração da Agenda $21^{13}$ (COELHO; GOLDEMBERG, apud GRANZIERA e REI, 2015), em cujo capitulo 7 da primeira seção, recomenda-se a adoção de planos para diminuir os efeitos negativos das migrações rurais que chegaram às cidades e a elaboração de avaliações do crescimento das cidades e seu impacto no meio ambiente, com a finalidade de aplicar critérios de urbanismo e gestão adaptados as necessidades e capacidades de recursos (ONU, 1992a).

Em 1996, vinte anos após a Conferência Habitat I, tem lugar em Istambul (Turquia) a segunda conferência (Habitat II), reunião que, por meio da Declaração de Istambul sobre Assentamentos Humanos, estabelece a chamada Agenda Habitat, na qual os Estados reafirmam a vontade de alcançar progressivamente o pleno direito de moradia adequada para $\operatorname{todos}^{14}$, o desenvolvimento sustentável dos assentamentos humanos e a promoção de mudanças nos sistemas de produção e consumo, assim como a conservação do patrimônio histórico, cultural e ambiental (ONU, 1996).

Em 2015, como resultado da conferência da ONU de 2012, chamada Rio+20, é elaborada a Agenda 2030 (SUSTAINABLE DEVELOPMENT GOALS FUND), como plano de ação de longo prazo onde os países signatários propõem dezessete objetivos, tendo em vista que o desenvolvimento em escala global esteja baseado em relação equilibrada entre as dimensões econômica, social e ambiental para que o mesmo seja sustentável (ONU, 2015), motivo pelo qual estas metas foram chamadas como Objetivos de Desenvolvimento Sustentável (ODS), que substituíram os Objetivos de Desenvolvimento do Milênio (ODM), de 1992.

A partir da leitura da Agenda 2030, é possível identificar que os objetivos estão intercomunicados, e seu sucesso depende do cumprimento de suas 169 metas. Há um objetivo, o ODS $11^{15}$, que é focado especificamente na questão urbana, reconhecendo o desenvolvimento urbano e a gestão sustentável como elementos fundamentais para manter a qualidade de vida da população e procurando trabalhar conjuntamente com as autoridades e comunidades locais no planejamento das cidades e assentamentos humanos, para que desta forma seja possível reduzir o impacto ambiental que atualmente exercem sobre o sistema climático global (Ibid, p. 12).

\footnotetext{
13 "A Agenda 21 pode ser definida como um instrumento de planejamento para a construção de sociedades sustentáveis, em diferentes bases geográficas, que concilia métodos de proteção ambiental, justiça social e eficiência econômica" (MINISTERIO DO MEIO AMBIENTE DO BRASIL, 25 nov. 2018).

${ }^{14}$ Conforme ao artigo 25 da Declaração Universal dos Direitos Humanos de 1948, "1. Todo ser humano tem direito a um padrão de vida capaz de assegurar a si e à sua família saúde, bem-estar, inclusive alimentação, vestuário, habitação, cuidados médicos e os serviços sociais indispensáveis e direito à segurança em caso de desemprego, doença invalidez, viuvez, velhice ou outros casos de perda dos meios de subsistência em circunstâncias fora de seu controle.".

${ }^{15} \mathrm{O}$ objetivo número 11 estabelece: "Tornar as cidades e os assentamentos humanos inclusivos, seguros, resilientes e sustentáveis". Tem como metas: a) Garantir o acesso de todos à habitação segura, adequada e a preço accessível; b) Proporcionar acesso a sistemas de transporte seguros, accessíveis e sustentáveis; c) Aumentar a urbanização inclusiva e sustentável; d) Fortalecer esforços para proteger e salvaguardar o patrimônio cultural e natural do mundo; e) Reduzir o número de mortes e pessoas afetadas por catástrofes; f) Reduzir o impacto ambiental negativo per capita das cidades, prestando especial atenção à qualidade do ar e gestão de resíduos municipais; g) Proporcionar acesso universal a espaços públicos seguros, inclusivos, acessíveis e verdes; h) Apoiar relações econômicas, sociais e ambientais positivas entre áreas urbanas, periurbanas e rurais reforçando o planejamento nacional e regional de desenvolvimento; i) Aumentar substancialmente o número de cidades e assentamentos humanos adotando e implementando políticas e planos integrados para a inclusão, a eficiência dos recursos, mitigação e adaptação às mudanças climáticas, a resiliência a desastres; j) Apoiar os países menos desenvolvidos por meio de assistência técnica e financeira, para construções sustentáveis e resilientes. (Ibid. p. 30-31).
} 
Finalmente, em 2016, no quadro da Conferência Habitat III, foi criada a Nova Agenda Urbana (NAU), na qual os Estados signatários estabeleceram uma série de compromissos com a forma de planejar as cidades durante os próximos vinte anos, dando ênfase à igualdade de oportunidades para todos, ao fim da discriminação e à importância das cidades mais limpas (ONU, 2016a), tópicos que são, com certeza, reafirmação e impulso dos ODS, fazendo parte do direito internacional na sua forma soft, direito de cumprimento difuso ou flexível para os Estados, porém mecanismo gerador de direito internacional derivado das relações entre eles.

Até o momento é possível observar como o planejamento das cidades está nas agendas dos Estados, sendo uma preocupação cada vez mais reiterada por sua relação direta com o desenvolvimento sustentável e a proteção do meio ambiente, mas é importante indicar que não são só os Estados os encarregados de participar desta denominada governança global, porque, de forma complementar às diferentes reuniões, instituições e instrumentos internacionais acima mencionados, existe participação forte por parte dos governos locais, da população, do setor social (GALINDO; MONTEIRO, 2016), cientistas, setor privado, organizações civis e não governamentais ${ }^{16}$.

Um exemplo do anterior é o funcionamento de The World Urban Campaing (WUC), plataforma de advocacia e parceria para aumentar a conscientização sobre a mudança urbana positiva a fim de alcançar cidades bem planejadas ${ }^{17}$. A WUC é importante fórum para colocar a agenda urbana nas diferentes políticas de desenvolvimento e atualmente fazem parte da mesma 180 parceiros e redes (Ibid), dentro dos quais é possível identificar organizações internacionais públicas e particulares, empresas, programas globais, universidades, fundações, institutos de pesquisa, entre outros mais.

Com a informação exposta até o momento, pode-se afirmar que existe verdadeira governança global em matéria de planejamento das cidades, focada em obter cidades mais sustentáveis que consigam garantir os direitos fundamentais das pessoas, mas é importante verificar se essa governança não poderia ser considerada como um regime internacional.

Nesse sentido, partido da definição de regime internacional colocada no item anterior, poderíamos afirmar que, apesar de, no presente caso, existirem princípios e inclusive procedimentos de tomada de decisões sobre o planejamento das cidades, a falta de normas e regras não permite falar da configuração de um regime internacional. É necessário ainda pensar se a construção ou criação de um regime internacional neste caso é requerida, já que muitas das recomendações e conteúdo das agendas estão sendo desenvolvidas desde os diferentes níveis locais de aplicação.

\section{A relação com o regime internacional das mudanças climáticas.}

Como mencionado no item 1, tanto a governança global como os diferentes regimes internacionais são dinâmicos, têm desenvolvimento com o correr do tempo e avanços em diferentes matérias vão acontecendo, razão pela qual não é possível entender que sejam uma criação estática e sem desenvolvimento algum.

\footnotetext{
${ }^{16}$ Um exemplo foi o processo preparatório da Conferencia Habitat III, que começou dois anos antes com a realização em 2014 do Urban Forum em Medellín (Colômbia) que contou com a presença de 22.000 participantes. Posteriormente foram realizadas três reuniões preparatórias (Precom), nas cidades de New York (2014), Nairóbi (2015) e Surabaya (2016), cujo desenvolvimento foi organizado ao redor de onze diferentes unidades de política urbana (Policy Units). (ONU, 2016b).

${ }^{17}$ Cfr. WORLD URBAN CAMPAING. Disponível em: <http://www.worldurbancampaign.org/> Acesso em: 25 nov. 2018.
} 
Essa característica de dinamismo faz que diferentes tipos de governança global estabeleçam relações, sendo igualmente provável a comunicação com alguns regimes internacionais focados em outros temas, mas que podem compartilhar objetivos, cujo cumprimento depende em grande parte da boa comunicação entre esses.

Um caso onde se apresenta essa comunicação é entre a GPC e o regime internacional das mudanças climáticas (RIMC), que será desenvolvida no presente item com a finalidade de demostrar sua interdependência e a existência de metas, objetivos e propósitos comuns.

Ressalte-se, a princípio, que o RIMC está focado nos diferentes problemas ambientais gerados pelo fenômeno do efeito estufa adicional na Terra e tem sua origem na Convenção Quadro das Nações Unidas Sobre Mudança Climática (Rio de Janeiro, 1992), e desenvolvimento no Protocolo de Quioto de 1997 e recentemente no denominado Acordo de Paris, assinado em 2015 durante a $\mathrm{COP}^{18} 21$.

Segundo Fernandes (2014, p. 38-45), é claro que muitas das alterações climáticas comumente são derivação de causas naturais, como o ciclo solar, a variação orbital, os impactos dos meteoritos e a deriva dos continentes, aproximando-se e afastando-se dos polos, além dos ciclos geológicos terrestres. Seguindo a anterior premissa, Farias $(2015$, p. 18) considera que um fenômeno natural necessário para a manutenção da temperatura média do planeta é o efeito estufa, entendido como uma reação física que permite ao planeta guardar o calor irradiado durante o dia, devolvendo-o à atmosfera durante a noite.

Contudo, os diferentes relatórios sobre a matéria ${ }^{19}$ e grande parte dos cientistas de todo o mundo coincidem em que algumas atividades antrópicas estão gerando aumento nas concentrações de gases efeito estufa $(\mathrm{GEE})^{20}$ e portanto aquele é o efeito estufa adicional, responsável pela intensificação das mudanças climáticas e suas consequências negativas no normal funcionamento dos sistemas naturais da terra ${ }^{21}$.

Desta forma, com certeza para falar de uma primeira relação entre a GPC e o RIMC, devese fazer referência aos tópicos meio ambiente e desenvolvimento sustentável, já que muitas das discussões sobre o modelo de desenvolvimentos das cidades tomam como base os efeitos da urbanização no meio ambiente e, como foi indicado anteriormente, um dos objetivos da GPC é o planejamento de cidades mais verdes e onde os direitos dos cidadãos tenham plena garantia.

A forma de planejar as cidades é tão importante na atualidade porque, segundo algumas previsões, espera-se que em 2050 o contingente populacional urbano seja maior do que a

\footnotetext{
${ }^{18}$ As Conferências das Partes (COP) da Convenção Quadro são realizadas cada ano e têm como objetivo desenvolver aqueles pressupostos e metas estabelecidas na Convenção e revisar o cumprimento dos mesmos, assim como propor novas formas de alcançá-los.

${ }^{19} \mathrm{O}$ capitulo primeiro do relatório IPCC 2018 estabelece que o aumento de consumo de materiais baseados em combustíveis fósseis e a mudança de estilos de vida é uma das principais causas de esgotamento dos recursos globais e o principal contribuinte para o aumento das emissões de gases de efeito estufa (GEE). Além disso, indica que as emissões de GEE aumentaram mais de 50\% desde 1990 até 2015, e reconhece também, como causas de emissão antrópicas, o consumo de energia, os processos industriais, a agricultura, o desmatamento, a silvicultura e a produção de resíduos. (IPCC, 2018)

${ }^{20}$ Alguns GEE reconhecidos pelo IPCC são o dióxido de carbono (CO2), gás metano ( $\left.\mathrm{CH} 4\right)$ e óxido nitroso (N2O). (Ibid).

${ }^{21}$ Esse fato é reconhecido desde a o mesmo texto da Convenção Quadro das Nações Unidas sobre Mudança do Clima de 1992, quando estabelece em suas considerações "Preocupadas com que atividades humanas estão aumentando substancialmente as concentrações atmosféricas de gases de efeito estufa, com que esse aumento de concentrações está intensificando o efeito estufa natural e com que disso resulte, em média, aquecimento adicional da superfície e da atmosfera da Terra e com que isso possa afetar negativamente os ecossistemas naturais e a humanidade" (ONU, 1992b)
} 
população mundial atual e que, em 2020 , na América Latina $90 \%$ da população seja urbana (FAVARÃO; COSTA, 2018), realidade que sem dúvida coloca o tema urbano como centro de mesa nas discussões internacionais.

De fato, na hora de definir quais aspectos urbanos que podem pressionar e afetar negativamente o meio ambiente, temos como exemplos os seguintes: a) aumento de população nas cidades e migrações do campo às cidades; b) consumo de energia; c) emissões de dióxido de carbono e outros gases de efeito estufa; d) crescimento sem controle das cidades e esgotamento de recursos naturais; e) pobreza e moradia irregulares nas cidades; f) produção e manejo de resíduos.

Tal lista, embora deva ser considerada uma aproximação e não possa ser entendida como um conjunto esgotado de problemas, permite concluir pela evidente relação entre a GPC e o RIMC, que se materializa nas emissões de GEE no planeta por parte das cidades e aglomerações urbanas (ONU, 2012).

Somado ao anterior, a pesquisa liderada por Moran, por meio da qual foi feito estudo das pegadas de carbono $(\mathrm{PC})^{22} \mathrm{em} 13.000$ cidades ao redor do mundo, concluiu que as 100 principais áreas urbanas contêm $11 \%$ da população mundial mas representam $18 \%$ das PC globais (MORAN, et al, 2018). Além disso, em 98 dos 187 países avaliados, as três principais áreas urbanas são responsáveis por mais de um quarto das PC nacionais (Ibid).

A relação acima mencionada é igualmente reconhecida pela própria NAU (Nova Agenda Urbana: Declaração de Quito sobre cidades e aglomerados urbanos sustentáveis para todos), quando em seu texto estabelece que os Estados assinantes da Declaração se comprometem a: a) reduzir as emissões de GEE e a poluição com a finalidade de facilitar a gestão sustentável dos recursos naturais das cidades (ONU, 2016c, p. 19); b) incentivar o desenvolvimento de energias renováveis, sustentáveis e economicamente accessíveis, edifícios energeticamente eficientes e a promover a conservação de energia, atividades essenciais para reduzir as emissões de GEE (Ibid, p. 22); c) integrar, dentro dos processos de desenvolvimento e planejamento urbano e territorial, a redução de risco de catástrofes e medidas e considerações de mitigação e adaptação às mudanças climáticas, incluindo entre outras questões a redução de GEE (Ibid, p. 27).

Portanto, cidades bem planejadas, com sistemas de transporte sustentáveis, fontes de energia renovável, bom manejo e disposição final dos resíduos, articuladas com os setores rurais, focadas na satisfação das necessidades primárias da população e sobretudo onde os espaços verdes e a proteção dos recursos naturais sejam prioridade e não exceção, como proposto nas discussões ao interior da GPC, são sem dúvida fundamentais para a materialização do RIMC, assim como para o cumprimento de suas metas e objetivos.

Neste ponto, é importante refletir se no cenário internacional e especificamente ao interior do RIMC está sendo considerado o importante papel que tem as cidades e seus governos locais para o cumprimento das metas do regime, já que, se é um fato que as mesmas são responsáveis por grande quantidade dos GEE, é ali que a aplicação de medidas terá maior impacto, sendo a participação dos atores locais ferramenta indispensável para o bom desenvolvimento do RIMC.

\section{Conclusões}

Embora os conceitos de governança global e regimes internacionais tenham semelhanças e aproximações porque ambos se referem a formas de obter soluções para problemas comuns no

\footnotetext{
${ }^{22}$ A chamada "pegada de carbono" mede a quantidade total de emissões de gases de efeito estufa causados direta e indiretamente por um indivíduo, organização, evento ou produto.
} 
cenário internacional, não é possível entendê-los como um conceito único, e resulta importante diferenciá-los especialmente a partir da generalidade e caráter amplo no qual baseia-se a governança, oposta ao foco presente nos regimes internacionais em uma questão específica.

Assim, uma tentativa de estabelecer a diferença entre governança global e regimes internacionais é abordar tais conceitos como gênero e espécie, mas no presente trabalho se prefere entender que os regimes internacionais são uma forma pela qual se desenvolve uma questão especifica ou problema comum presente ao interior de um sistema de governança.

Tratar da governança global no planejamento das cidades poderia em princípio parecer sem sentido, porque normalmente a forma em que se planejam as cidades é o resultado de um conjunto de atividades de aplicação local, mas no presente artigo foi possível, a partir do estudo de instrumentos normativos internacionais e discussões no cenário internacional envolvendo diversos atores, tanto públicos como privados, estabelecer que o desenvolvimento das cidades e seu planejamento fazem parte de um verdadeiro sistema de governança global.

De fato, essa forma de governança global abrange não só discussões internacionais focadas na matéria urbana, como podem ser entendidas as diferentes conferências Habitat celebradas no quadro da ONU, mas também os relatórios, reuniões, debates e declarações da área ambiental que até o momento destacaram a importância do adequado planejamento das cidades com a finalidade de melhorar indicadores ambientais globais e também a sustentabilidade das cidades e qualidade de vida das pessoas.

Vale a pena destacar que na GPC a participação de atores não estatais, além de ser necessária, é evidente. É necessária porque as diferentes medidas a adotar têm que ser aplicadas pelos governos locais e terão influência direta no dia a dia das pessoas, razão pela qual a presença destes atores, seja de forma individual ou organizada, é imperativa para obter os melhores resultados. É evidente pois, como foi observado, o processo de preparação das diferentes conferências Habitat da ONU está baseado em reuniões preparatórias e fóruns com massiva participação de cidadãos e organizações sociais, circunstância que também está permitindo a criação de redes de parceria preocupadas em colocar sobre a mesa o tema de planejamento das cidades.

Por outro lado, embora se possa constatar o desenvolvimento das discussões sobre as problemáticas urbanas no cenário internacional e seja possível falar da existência de uma verdadeira governança global focada no planejamento das cidades, ela não pode ser considerada como um regime internacional devido à inexistência de normas e regras no seu conteúdo.

O dinamismo presente, tanto na governança global como nos regimes internacionais, se manifesta em diálogos e relações entre os mesmos, sempre que existam tópicos e preocupações comuns, assim como objetivos e metas cujo cumprimento resulta interdependente, tal como acontece entre a GPC e o RIMC.

Em síntese, o meio ambiente e o desenvolvimento sustentável são a principal ponte de conexão entre a GPC e O RIMC, relação que eleva a importância das cidades e seu planejamento para o cumprimento das metas estabelecidas no regime, e é cada vez mais importante refletir se as atividades desenvolvidas pelos governos locais estão sendo levadas em conta e tendo consequência na abordagem das questões ambientais.

\section{Referências}

BENTO, Leonardo Valles. Governança Global: Uma abordagem conceitual e normativa das relações internacionais em um cenário de interdependência e globalização. (Tese de Doutorado). 
Universidade Federal de Santa Catarina: 2007. Disponível em: <https://repositorio.ufsc.br/xmlui/handle/123456789/89641> Acesso em: 24. Nov. 2018.

BRESSER-PEREIRA, Luiz Carlos. Estado, Estado-Nação e formas de intermediação política. São Paulo (SP), 2017. Disponível em: <http://www.scielo.br/pdf/ln/n100/1807-0175-In-10000155.pdf> Acesso em: 24. Nov. 2018.

FARIAS, Valéria Cristina. Regime Internacional de Mudanças Climáticas: Ações climáticas e paradiplomacia ambiental do estado de São Paulo. (Tese de Doutorado). Universidade Católica de Santos: 2015.

FAVARÃO, Cesar B.; COSTA, Marco Aurélio. "Governança e Políticas Nacionais Urbanas: Capacidade e Desenvolvimento Institucional". Em: COSTA, Marco Aurélio, THADEU, Marcos e FAVARÃO, Cesar $B$ (org). A Nova Agenda Urbana e o Brasil: Insumos para sua construção e desafios a sua implementação. Brasília, IPEA, 2018. Disponível em:

http://www.ipea.gov.br/portal/images/stories/PDFs/livros/livros/180529 a nova agenda urban a e o brasil.pdf. p. 45-58. Acesso em 25 nov. 2018.

GALINDO, Ernesto; MONTEIRO, Roberta Amanajás. "Nova Agenda Urbana no Brasil à Luz da Habitat III". Em: Boletim regional, urbano e ambiental. No. 15, 2016. IPEA. Disponível em:

$<$ http://repositorio.ipea.gov.br/bitstream/11058/7102/1/BRU_n15_Nova.pdf> Acesso em: 25. nov. 2018.

GONÇALVES, Alcindo e COSTA, José Augusto Fontoura. Governança Global e Regimes Internacionais. São Paulo (SP): Editora Almedina Brasil Ltda., 2011

GONÇALVES, Alcindo e REI, Fernando de (Coord.). Governança e Paradiplomacia Ambiental. Santos (SP): Editora Universitária Leopoldianum, 2015.

GRANZIERA, Maria Luiza Machado; REI, Fernando de (Coord.). Direito Ambiental Internacional: Avanços e Retrocessos 40 Anos de Conferências das Nações Unidas. São Paulo: Atlas, 2015.

HASENCLEVER, Andreas; MAYER, Peter; RITTBERGER, Volker. Theories of International Regimes. Cambridge Studies in International Relations. n. 55. Cambridge: Cambridge University Press, 1997.

IPCC. Global Warming of $1.5^{\circ} \mathrm{C}$ : An IPCC Special Report on the impacts of global warming of $1.5^{\circ} \mathrm{C}$ above pre-industrial levels and related global greenhouse gas emission pathways, in the context of strengthening the global response to the threat of climate change, sustainable development, and efforts to eradicate poverty. 2018. Disponível em: <http://www.ipcc.ch/pdf/specialreports/sr15/sr15_chapter1.pdf>

IVANOVA, Maria. "O PNUMA e a Governança Ambiental Global". Em: CADERNOS ADENAUER. Governança Global. Ano IX, n. 3. Rio de Janeiro: Fundação Konrad Adenauer, 2009.

KLUG, L.; MARENGO, J. A.; LUEDEMANN, G. Mudanças climáticas e os desafios brasileiros para implementar a Nova Agenda Urbana. In: COSTA, M. A. (Org.). O Estatuto da Cidade e a Habitat III: um balanço de quinze anos de política urbana no Brasil e a Nova Agenda Urbana. Brasília: Ipea, 2016.

KRASNER, Stephen D. "Structural causes and regime consequences: regimes as intervening variables". Em: KRASNER, Stephen D. (Ed.). International Regimes. Ithaca e Londres: Cornell University Press, 1983.

MAUAD, Ana Carolina Evangelista. Governança Global: Intersecções com paradiplomacia em meio à crise climática. BIB, São Paulo, n. 78, 2014. Disponível em: $<$ https://www.anpocs.com/index.php/bib-pt/bib-78/9990-governanca-global-interseccoes-comparadiplomacia-em-meio-a-crise-climatica/file> Acesso em: 27 nov. 2018. 
MINISTÉRIO DO MEIO AMBIENTE DO BRASIL. Agenda 21. Disponível em: <http://www.mma.gov.br/responsabilidade-socioambiental/agenda-21>Acesso em: 25 nov. 2018.

MORAN, Daniel et al. Carbon footprints of $\mathbf{1 3 . 0 0 0}$ cities. Environmental Research Letters. n. 23 (2018). Disponível em: <http://iopscience.iop.org/article/10.1088/1748-9326/aac72a/pdf> Acesso em: 26 nov. 2018.

ONU. Declaração de Estocolmo sobre o Meio Ambiente Humano. 1972. Disponível em: < https://www.silex.com.br/leis/normas/estocolmo.htm> Acesso em: 25. Nov. 2018.

The Vancouver Declaration On Human Settlements. 1976. Disponível em: <http://pfdc.pgr.mpf.mp.br/atuacao-e-conteudos-de-apoio/legislacao/moradia-

adequada/declaracoes/declaracao-sobre-assentamentos-humanos-de-vancouver/view> Acesso em: 25 nov. 2018.

Carta Mundial da Natureza. $1982 . \quad$ Disponível em:<http://www.meioambiente.pr.gov.br/arquivos/File/agenda21/Carta_Mundial_para_Naturez a.pdf $>$ Acesso em: 25. Nov. 2018.

Disponível

Informe de la Comisión Mundial sobre el Medio Ambiente y el Desarrollo. 1987.

<http://www.ecominga.uqam.ca/PDF/BIBLIOGRAPHIE/GUIDE_LECTURE_1/CMMAD-Informe-

Comision-Brundtland-sobre-Medio-Ambiente-Desarrollo.pdf> Acesso em: 25 nov. 2018.

\section{2a. \\ Programa 21: Capítulo 7. Fomento del Desarrollo Sostenible de los Recursos Humanos. \\ <http://www.un.org/spanish/esa/sustdev/agenda21/agenda21spchapter7.htm> Acesso em: 25 nov. 2018.}

. Convenção Quadro das Nações Unidas sobre Mudança do Clima. Rio de Janeiro, 1992b. Disponível em: <http://www.planalto.gov.br/ccivil_03/decreto/D2652.htm> Acesso em 25 nov. 2018.

Declaração de Istambul sobre Assentamentos Humanos. 1996. Disponível em: <https://undocs.org/es/A/CONF.165/14> Acesso em: 25 nov. 2018.

. ONU-HABITAT: Energia. 2012. Disponível em: <https://es.unhabitat.org/temasurbanos/energia/> Acesso em 26 nov. 2018.

. Transformando Nosso Mundo: A Agenda 2030 para o Desenvolvimento Sustentável. Nova lorque, 2015. Disponível em: <https://nacoesunidas.org/wpcontent/uploads/2015/10/agenda2030-pt-br.pdf> Acesso em: 25 nov. 2018.

. Habitat III: países adotam nova agenda para urbanização sustentável. 2016a. Disponível em: <https://nacoesunidas.org/habitat-iii-paises-adotam-nova-agenda-para-urbanizacaosustentavel/> Acesso em: 15 nov. 2018.

. HABITAT III: The preparatoy process. 2016b. Disponível em: <http://habitat3.org/thenew-urban-agenda/preparatory-process/> Acesso em: 25 nov. 2018.

Nova Agenda Urbana: Declaração de Quito sobre cidades e aglomerados urbanos sustentáveis para todos. Quito, 2016c. p. Disponível em: <http://habitat3.org/wpcontent/uploads/NUA-Portuguese.pdf > Acesso em: 25 nov. 2018.

. ONU-HABITAT: Programa das Nações Unidas para os Assentamentos Humanos. 2018.

Disponível em: <https://nacoesunidas.org/agencia/onuhabitat/> Acesso em: 25 nov. 2018. 
SUSTAINABLE DEVELOPMENT GOALS FUND. From MDGs to SGDs. Disponível em: <http://www.sdgfund.org/mdgs-sdgs> Acesso em: 25 nov. 2018.

WORLD URBAN CAMPAING. Disponível em: <http://www.worldurbancampaign.org/> Acesso em: 25 nov. 2018.

YOUNG, Oran R. Institutional Dynamics: Emergent Patterns in International Environmental Governance. Cambridge and London: The MIT Press, 2010.

Trabalho enviado em 26 de fevereiro de 2019

Aceito em 20 de abril de 2020 